\title{
Quality Assessment of a 2D FE Based Lumped Parameter Electric Motor Thermal Model Using 3D FE Models
}

\author{
Jasper Nonneman, Ilya T'Jollyn, Peter Sergeant, Michel De Paepe
}

\begin{abstract}
This paper presents an advanced thermal lumped parameter model (LPM) for a switched reluctance motor for which the accuracy of the results is verified with a 3D finite element (FE) simulation. An advanced lumped parameter model is proposed, which extracts a 2D LPM from a 2D FE simulation and extends this 2D LPM into 3D based on the regular LP techniques. The assumptions and simplifications in de 3D LPM are verified with a 3D FE model by comparing the simulated average and maximum component temperatures of the models. The comparison shows a deviation of $0.2 \%$ on the maximum of the average component temperatures (rotor) and $0.1 \%$ on the maximum of the maximum component temperatures (winding). It is concluded that the proposed advanced 3D LPM is an efficient and accurate method when compared to a 3D FE model.
\end{abstract}

Index Terms- electric machines, electronics cooling, finite element analysis, numerical simulation, thermal management.

\section{INTRODUCTION}

$\mathrm{E}$ LECTRICAL alternatives to combustion engines in the transport sector become more and more popular. These electrified drivetrains, consisting of batteries, power electronics and an electric motor, experience the trend to get more power dense. As a result, the cooling limit of the conventional cooling methods, such as a liquid jacket, is approached and excessive temperatures are attained within the components of the drivetrain [1]

Several cooling methods and thermal designs are investigated in scientific literature to improve the cooling of the electric motor and to be able to go to higher power densities [2]. Firstly, the thermal machine design can be improved by reducing the thermal resistance from the point where the maximum temperature occurs, which is mostly within the winding, to the location of the cooling method. This can be done by a different winding design (using rectangular [3] or edgewise conductors [4]) and impregnation [5], by reducing the thermal resistance from winding to stator iron with conductive heat paths [6] or from end winding to housing by potting strategies [7].

Secondly, there is the possibility to bring the cooling method closer to the hot spot location compared to a conventional jacket cooling. This can be done by more direct liquid cooling methods. For the windings there are several

This research was supported by Flanders Make, the strategic research centre for the manufacturing industry, and the HERMESFONDS in the framework of the Hipercool project (HBC.2016.0463).

J. Nonneman, I. T'Jollyn, P. Sergeant and M. De Paepe are with the Department of Electromechanical, Systems and Metal Engineering, Ghent University, Sint-Pietersnieuwstraat 41, 9000 Ghent, Belgium (e-mail: options such as direct coil cooling (dry [8] and wet [3]) and end winding cooling (immersed [2] or spray cooling [9]). When the hot spot temperature occurs within the rotor, hollow shaft cooling or a heat pipe in the shaft $[2,6]$ can be used.

The impact on the motor temperature of these modifications is very difficult to compare based on the described results, because deviating geometries and boundary conditions were used in the studies. Further, the effect of a certain modification will be dependent on the motor geometry and size. A numerical model can be used to make a comparison of the various modifications, which can be a lumped parameter model (LPM) or finite element model (FEM) with or without computational fluid dynamics (CFD) [10]. LP models are fast and simple, but are less accurate than FEM and CFD, while the latter increase the complexity and computational time of the simulations [11]. Within this paper, an advanced thermal LPM for a switched reluctance motor (SRM) is presented and developed, based on a 2D FE simulation, which combines the benefits of a LPM and FEM.

As a result of the choice for a LPM, several simplifications and assumptions were made to be able to develop the 3D LP model. The impact on the model accuracy of these assumptions will be studied within this paper. This can be done by comparing the simulation results with experimental measurements or other numerical models. To exclude possible issues with the accuracy of the measurements within electric machines and uncertainty of the material properties and thermal contact resistances of components [12], it was decided to verify the 3D LPM results with the results of a 3D FE simulation in OpenFOAM based on exactly the same inputs.

In the following sections, first the verification case is described, which is a Switched Reluctance Motor cooled by a jacket. Next, a detailed overview of the proposed 3D LPM and 3D FEM which will be used for the verification is given. Finally, the results of the 3D LPM are compared to the results of the 3D FE simulation and the accuracy of the proposed model is discussed.

\section{ELECTRIC MOTOR VERIFICATION CASE}

The studied motor in this paper is a switched reluctance motor (SRM) as shown in Fig. 1 with the motor properties as

Jasper.Nonneman@UGent.be,

Peter.Sergeant@UGent.be and Michel.DePaepe@UGent.be).

Ilya.TJollyn@UGent.be,

J. Nonneman, I. T'Jollyn, P. Sergeant and M. De Paepe are also with Flanders Make, Core Lab MotionS, Gaston Geenslaan 8, 3001, Leuven, Belgium 
described in TABLE I. The stator core is laminated and consists of six poles with concentrated windings. A Nomex liner $(0.1 \mathrm{~mm})$ is included between the windings and stator core to prevent short circuits. The windings completely fill the remaining space in the slot between the stator poles. The rotor core consists solely of laminations and has four poles.

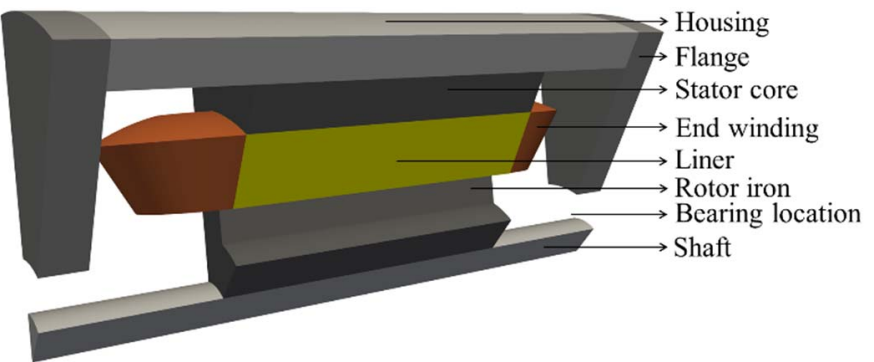

Fig. 1. Switched reluctance motor overview (half of a stator and rotor tooth shown).

Most of the heat in the motor is generated within the stator windings by Joule heating in the copper conductors. The other heat losses originate from iron losses in the stator and rotor laminations and frictional losses in the bearings and airgap. Within the verification case, the generated heat in the motor is transferred to a cooling jacket within the housing of the motor. The jacket cooling method will be implemented as an equivalent heat transfer coefficient onto the outer surface of the housing in the active region.

TABLE I

SWITCHED RELUCTANCE MOTOR PROPERTIES [13]

\begin{tabular}{c|c} 
Stator/rotor poles & $6 / 4$ \\
\hline Axial active length & $80 \mathrm{~mm}$ \\
\hline Shaft diameter & $20 \mathrm{~mm}$ \\
\hline Rotor outer diameter & $62 \mathrm{~mm}$ \\
\hline Stator outer diameter & $120 \mathrm{~mm}$ \\
\hline Airgap thickness & $0.25 \mathrm{~mm}$ \\
\hline Yoke thickness & $11 \mathrm{~mm}$ \\
\hline Pole width & $17.5 \mathrm{~mm}$ \\
\hline Rated speed & $3000 \mathrm{rpm}$ \\
\hline Rated power & $3 \mathrm{~kW}$
\end{tabular}

\section{3D LUMPED PARAMETER MODEL}

This section will describe the proposed 3D thermal lumped parameter model. The model assumes axial symmetry between the different stator/rotor poles and as such models only half of a stator and rotor tooth. The method combines the advantages of a finite element model and a lumped parameter model. Within the axial direction and at the end plates, the geometry of the motor is relatively simple and low thermal gradients occur due to the relatively high thermal conductivity of the components. Therefore, the lumped parameter thermal network as shown in Fig. 2 (left) can be used to model the conduction in this direction. The thermal resistances $R_{1}$ and $R_{2}$ of this network can be approximated by simple analytical equations for $1 \mathrm{D}$ conduction in a solid with a constant thermal conductivity without heat generation, for either a constant cross section (1) or in a hollow cylinder (2). The thermal network as shown in Fig. 2 (left) cannot be used directly to model components with heat generation. As a solution to that, the method proposed by Wrobel et al. [14] is used, where the heat generation is taken into account by implementing an additional thermal resistance $\mathrm{R}_{\mathrm{n}}$ within the network as shown in Fig. 2 (right) which is negative (3).
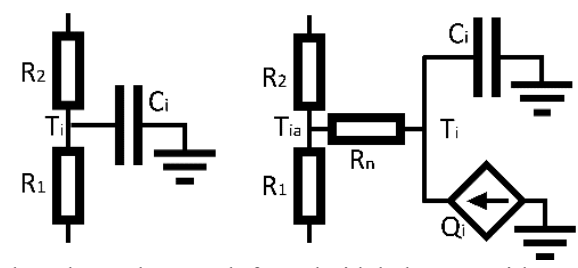

Fig. 2. Equivalent thermal network for cuboidal element without (left) and with (right) heat generation

$$
\begin{gathered}
R_{1}=R_{2}=\Delta L /(2 k A) \\
R_{\text {axial }, c y l}=\frac{\ln \left(r_{o} / r_{i}\right)}{2 \pi \Delta L k} \\
R_{n}=-\Delta L /(6 k A)
\end{gathered}
$$

Within these networks and equations, $T_{i}$ is the node temperature, $\mathrm{C}_{\mathrm{i}}$ the node heat capacity, $\dot{\mathrm{Q}}_{\mathrm{i}}$ the node heat generation, $\mathrm{T}_{\mathrm{i} \text { a }}$ an additional node temperature, $\Delta \mathrm{L}$ the axial length, $\mathrm{k}$ the thermal conductivity, A the cross sectional area and $r_{o}$ and $r_{i}$ respectively the outer and inner radius of the hollow cylinder.

In the radial and tangential direction, the thermal conductivity of the winding is much smaller compared to the axial direction and together with contact resistances and interface materials, this results in high and 2D temperature gradients within these directions. It is more difficult to apply this lumped parameter technique in these directions with sufficiently accurate results, because of the complex geometry and thermal connections together with the high thermal gradients in these directions. The proposed solution in this work is to use a $2 \mathrm{D} \mathrm{FE} \mathrm{model} \mathrm{to} \mathrm{accurately} \mathrm{determine} \mathrm{the}$ temperature distribution in these directions and to extract a 2D LPM from this model. The LPM is extracted from the 2D FE simulation by first setting up a coarse discretization on top of the different components of the 2D geometry. The cells resulting from this coarse discretization serve as a basis for the different thermal nodes of the 2D LPM. Within components where a high temperature gradient occurs or the maximum temperature should be known accurately, the amount of cells of the coarse discretization can be increased to improve the accuracy. The LPM is then created by calculating the thermal resistances $R_{i j / j i}$ from the average temperature $T_{i / j, \text { avg }}$ of the coarse cells and the heat flux $\dot{\mathrm{Q}}_{\mathrm{ij}}$ between adjacent cells, using (4):

$$
R_{i j}=R_{j i}=\frac{\left|T_{i, a v g}-T_{j, a v g}\right|}{\dot{Q}_{i j}}
$$

The 2D FE simulation is performed with the software package FEMM and a Matlab model is set up to be able to automatically draw, mesh and solve the temperature distribution in FEMM. Further, the Matlab model postprocesses the 2D FE results by extracting the average cell temperatures, heat fluxes, cross-sectional areas and boundary lengths. The latter two can be used further in the model for the 
following purposes:

- The calculation of the axial thermal resistances.

- The calculation of the (convective) thermal resistances to external media (coolant, ambient air), based on correlations from scientific literature.

- The calculation of contact resistances, which are not included within the FEMM simulation.

It should be mentioned here that the amount of stator and rotor poles is usually different and as such, one rotor tooth cannot simply be thermally connected to one stator pole. To overcome this issue, the stator and rotor pole are not directly connected within the 2D FE simulation, but a convective boundary condition is applied on the stator and rotor surfaces that are in contact with the airgap. The airgap temperature is then iterated until the heat balance between the two components, scaled to the full motor, is closed.

Fig. 3 shows an example of the geometry, coarse discretization (blue lines) and fine mesh used for the 2D FE simulation (yellow lines) at the left side, and the temperature distribution resulting from the FE simulation at the right side.
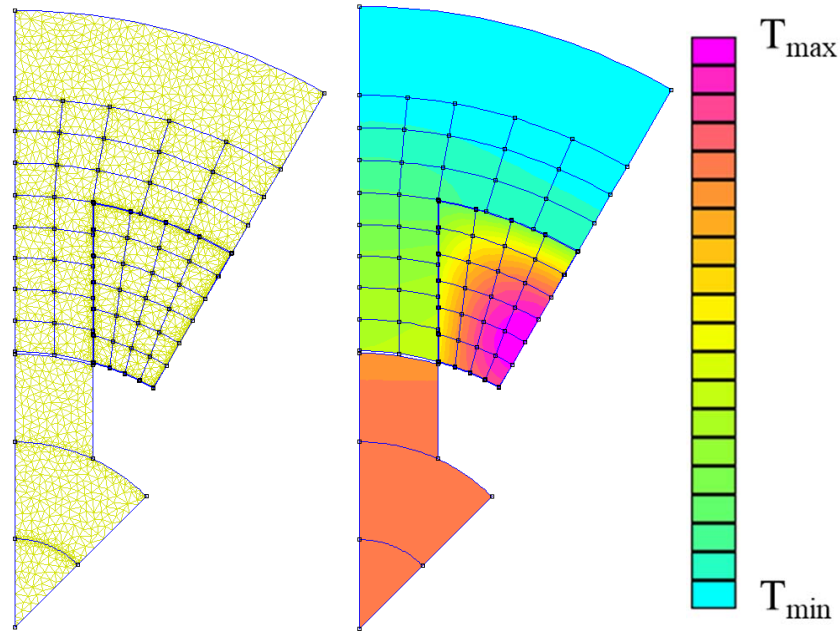

Fig. 3. Example of 2D FE simulation with FEMM of a half stator/rotor tooth: geometry, coarse discretization and fine mesh (left) and temperature distribution (right)

When changing the geometry or thermal properties in the radial or tangential direction, the $2 \mathrm{D}$ FE simulation should be redone to obtain the correct $2 \mathrm{D}$ LP model. However, since the computational time of the FE simulation is short, adjustments of either the geometry or thermal resistances can easily be performed if necessary to analyze, e.g., different parameter ranges or the sensitivity of the solution to these parameters.

For the end windings, the same internal connections in radial direction are used as these obtained for the active part. It is assumed that the liners are not present in the end winding region because no short circuit can occur here. The combination of this 2D LPM based on the 2D FE model, with the analytical approach as described in the beginning of this section, results in a full 3D thermal LPM for the whole motor. To be able to determine the maximum temperature in the axial direction more accurately, the motor can be split into two or more slices in the axial direction, resulting in a multi-slice 3D LPM. This combination is also done within Matlab and the thermal conductance matrix method is used to construct and solve the whole thermal network, where the discretized heat balance between the nodes of the coarse discretization is written in matrix formulation (5). It cannot be used directly because of the inequality in stator and rotor poles. As a solution, the thermal resistances and heat inputs in the rotor part are rescaled to the amount of stator poles.

This thermal conductance matrix method is based on (5)(10) where $\mathrm{K}$ is the thermal conductance matrix, $\mathrm{T}$ is the array of the node temperatures, $\mathrm{b}$ is an array dependent on heat dissipation, heat transfer to external media and the temperature at the previous time iteration $t$ and $\mathrm{i}, \mathrm{j}, \mathrm{n}$ are node indices. Further, $\mathrm{R}_{\mathrm{ij}}$ is the thermal resistance and $\mathrm{K}_{\mathrm{ij}}$ the thermal conductance between the nodes, $R_{i, \text { ext }}$ the thermal resistance to the external temperature $T_{i, \text { ext }}$ of the medium, $h_{i}$ the convective heat transfer coefficient between surface and medium and $\mathrm{A}$ the available heat transfer area.

$$
\begin{gathered}
K=\left[\begin{array}{cccc}
K_{11} & K_{12} & \ldots & K_{1 n} \\
K_{21} & K_{22} & \ldots & K_{2 n} \\
\vdots & \vdots & \ddots & \vdots \\
K_{n 1} & K_{n 2} & \ldots & K_{n n}
\end{array}\right], T=\left[\begin{array}{c}
T_{1, t} \\
T_{2, t} \\
\vdots \\
T_{n, t}
\end{array}\right], b=\left[\begin{array}{c}
b_{1, t} \\
b_{2, t} \\
\vdots \\
b_{n, t}
\end{array}\right] \\
K_{i j}=K_{j i}=\frac{1}{R_{i j}}=\frac{1}{R_{j i}} \\
K_{i i}=-\left(\sum_{j \neq i}^{n} K_{i j}+\sum \frac{1}{R_{i, e x t}}+\frac{c_{i}}{\Delta t}\right) \\
b_{i, t}=-\left(\dot{Q}_{i}+\sum \frac{T_{i, e x t}}{R_{i, e x t}}+\frac{C_{i}}{\Delta t} T_{i, t-1}\right) \\
R_{i, e x t}=1 /\left(h_{i} A\right)
\end{gathered}
$$

Transient simulations with time step $\Delta \mathrm{t}$ can be performed with this model, where $t$ indicates the iteration in time. Out of this $\mathrm{b}$ and $\mathrm{K}$, the new temperatures at the end of moment $\mathrm{t}$ can be calculated. However, only the steady-state model will be studied in this work.

\section{3D FINITE ELEMENT VERIFICATION CASE}

The described 3D LPM of the previous section is based on several assumptions and approximations to estimate the conductive resistances within the motor. Together with the method of obtaining the radial and tangential thermal resistances from the $2 \mathrm{D}$ FE simulation, these should be verified with a reference whose results are considered reliable. Experimental measurements or other numerical models can be used as a reference to verify the developed model. Possible issues with experimental measurements are the accuracy of the measurements within electric machines and uncertainty of the material properties and thermal contact resistances of components [12]. To exclude these uncertainties within the model verification, another reliable numerical model will be used to simulate the $3 \mathrm{D}$ conduction within the motor test case.

Several software packages are capable of simulating steady-state heat conduction in $3 \mathrm{D}$ by solving the heat equation given by (11). Within this paper, the open-source software OpenFOAM 6 is used for the generation of the 3D mesh and solution of the heat equation (11) in every component.

$$
\frac{k}{\rho c_{p}} \nabla^{2} T+\frac{\dot{q}}{\rho c_{p}}=\frac{\delta T}{\delta t}
$$


The mesh is generated by using the OpenFOAM blockMesh utility, which creates parametric meshes with grading and curved edges, based on the splitting of the geometry in hexahedral blocks. The following has been taken into account during the preparation of the simulation:

- Exactly the same geometrical inputs as the 3D LPM model are used. Similar to the 3D LPM model, only half of a stator and rotor tooth is modelled.

- Anisotropic thermal conductivity is taken into account within the stator iron, rotor iron, winding and end windings.

- The end windings were originally following a semicircular shape in the model. However, a bug was found within the OpenFOAM software, causing heat balance issues when heat generation, anisotropic thermal conductivity and cylindrical coordinates are combined. The bug could not yet be solved so as a temporary solution for this paper, the end windings were straightened.

- Convective heat transfer on the outer housing surface in the active motor region.

- Uniform volumetric heat generation within the heat generating components.

- Contact resistances between the different components.

- The stator and rotor part are thermally coupled at the airgap (convection) and bearing (interface resistance). Similar to the 2D FE simulation, the coupling is done outside OpenFOAM by iteration of the airgap and bearing temperature until a closed heat balance is achieved.

To solve the governing equation of the problem, the builtin solver chtMultiRegionFoam is used, which is capable of solving for enthalpy in combined heat transfer problems with multiple regions both steady state and transient.

\section{3D LPM VERIFICATION}

In this section, the steady-state verification of the 3D LPM with the 3D FE reference simulation is described. The models will simulate the same verification case with exactly the same geometrical and thermal inputs, which was described in the electric motor verification case section. The used model inputs are taken based on a real-life application and the parameter values result from scientific literature or correlations. Considering this, contact resistances between the different components were also taken into account, which result from the imperfect contact of two surfaces. An overview of the input parameters can be found in TABLE II. The mean end winding length in the models is calculated such that the end winding volume is the same as for a semicircular shape.

\section{A. Models Convergence and Accuracy Checks}

Both models are checked on accuracy and convergence before comparing the models with each other. This section gives an overview of the different checks for each model:

\section{I) 3D Lumped Parameter Model:}

Within the 2D FE simulation part of the 3D LPM model, a check is performed to verify whether the 2D LPM correctly reconstructs the temperature distribution of the $2 \mathrm{D} F E$ simulation with FEMM. Therefore, the same inputs are applied at the 2D LPM and the conductance matrix is constructed for the $2 \mathrm{D}$ axial slice. From the result, the difference in temperature between the 2D FE and 2D LPM is calculated and the absolute deviations on the maximum temperatures in winding, stator iron and rotor are reported. These differences are defined as $\left(\mathrm{T}_{\max , 2 \mathrm{D}} \mathrm{FE}_{-} \mathrm{T}_{\max , 2 \mathrm{D}}\right.$ $\mathrm{LPM}) /\left(\mathrm{T}_{\max , 2 \mathrm{D} \mathrm{LPM}}-\mathrm{T}_{\text {coolant }}\right)$ and are lower than $2 \%$ in the winding, $2.6 \%$ in the stator core and $9.7 \%$ in the rotor core for the studied cases. These values are the worst case where only one coarse node is used for the coil, stator and rotor. When using 2 or more nodes, the difference decreases drastically: $0.8 \%$ in the coil, $2.6 \%$ in the stator core and $0.7 \%$ in the rotor core.

The heat balance is checked after calculation of the $3 \mathrm{D}$ LPM and is smaller than $2 \times 10^{-14} \mathrm{~W}$ after each simulation. Furthermore, the sensitivity of the amount of nodes in the coarse discretization is checked. Therefore, a sweep of the amount of nodes in the radial and tangential direction and axial direction is performed with the 3D LPM model. Within this sweep, the amount of nodes is gradually increased within the radial and tangential direction of the winding and stator iron tangential nodes in the winding is used as a reference and the other refinements in the radial and tangential direction are

TABLE II

MODEL PARAMETERS FOR 3D LPM VERIFICATION

Geometrical properties

\begin{tabular}{|c|c|}
\hline Mean end winding length & $23.3 \mathrm{~mm}$ \\
\hline End space width & $30 \mathrm{~mm}$ \\
\hline Flange thickness & $10 \mathrm{~mm}$ \\
\hline Bearing outer diameter & $42 \mathrm{~mm}$ \\
\hline Bearing thickness & $20 \mathrm{~mm}$ \\
\hline Liner thickness & $0.1 \mathrm{~mm}$ \\
\hline \multicolumn{2}{|c|}{ Contact/interface resistances } \\
\hline Bearing equivalent airgap & $0.3 \mathrm{~mm}[15]$ \\
\hline Housing-stator yoke & $1384 \mathrm{~mm}^{2} \mathrm{~K} / \mathrm{W}[15]$ \\
\hline Shaft-rotor yoke & $1384 \mathrm{~mm}^{2} \mathrm{~K} / \mathrm{W}[15]$ \\
\hline Housing-flange & $1384 \mathrm{~mm}^{2} \mathrm{~K} / \mathrm{W}[15]$ \\
\hline Winding-liner & $600 \mathrm{~mm}^{2} \mathrm{~K} / \mathrm{W}[16]$ \\
\hline Stator core-liner & $600 \mathrm{~mm}^{2} \mathrm{~K} / \mathrm{W}[16]$ \\
\hline \multicolumn{2}{|c|}{ Thermal conductivities } \\
\hline Housing, Flange & $200 \mathrm{~W} / \mathrm{mK}$ \\
\hline Core radial/tangential & $22.2 \mathrm{~W} / \mathrm{mK}[14]$ \\
\hline Core axial & $4.9 \mathrm{~W} / \mathrm{mK}[14]$ \\
\hline Shaft & $43 \mathrm{~W} / \mathrm{mK}$ \\
\hline Liner & $0.1 \mathrm{~W} / \mathrm{mK}$ \\
\hline Winding radial/tangential & $1.03 \mathrm{~W} / \mathrm{mK}[5]$ \\
\hline Winding axial & $250 \mathrm{~W} / \mathrm{mK}[5]$ \\
\hline \multicolumn{2}{|c|}{ Steady-state heat losses } \\
\hline Winding & $422.2 \mathrm{~W}[13]$ \\
\hline Stator core & $221.5 \mathrm{~W}[13]$ \\
\hline Iron core & $66.1 \mathrm{~W}[13]$ \\
\hline Airgap & $0.24 \mathrm{~W}[17]$ \\
\hline Bearing & $20 \mathrm{~W}$ \\
\hline \multicolumn{2}{|c|}{ Cooling/convection } \\
\hline $\begin{array}{l}\text { Airgap convective heat } \\
\text { transfer coefficient }\end{array}$ & $139.7 \mathrm{~W} / \mathrm{m}^{2} \mathrm{~K}[18]$ \\
\hline $\begin{array}{l}\text { Jacket convective heat } \\
\text { transfer coefficient }\end{array}$ & $3000 \mathrm{~W} / \mathrm{m}^{2} \mathrm{~K}$ \\
\hline Jacket coolant temperature & $40^{\circ} \mathrm{C}$ \\
\hline
\end{tabular}


related to this parameter. Within the axial direction, the amount of axial slices in the active part is used as a reference and the axial slices in the end windings are taken as half of this reference. The results of this sweep are shown for the average component temperatures in Fig. 4 and difference between maximum and average temperature in Fig. 5.

Fig. 4 shows that the influence of the amount of radial/tangential nodes is rather small for the average component temperature, except when less than five nodes are used. Further increasing the amount of nodes does not greatly improve the accuracy and increases the contribution of numerical errors of FEMM. When comparing Fig. 4 (left) with Fig. 4 (right), which are identical except for the amount of axial nodes, it can be concluded that the amount of axial slices only has a minor effect on the average component temperatures.

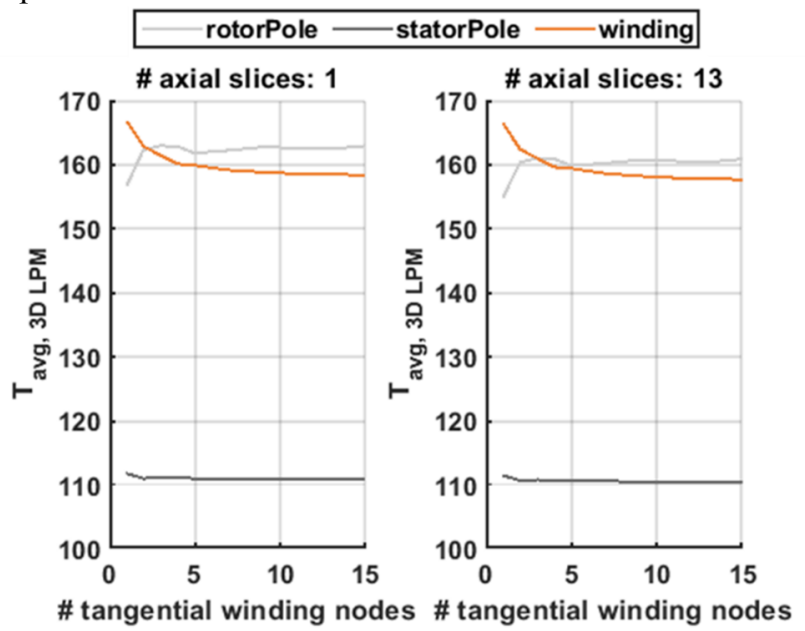

Fig. 4. Effect of the amount of radial, tangential and axial nodes on the average component temperature.

Fig. 5 shows that the amount of nodes in radial/tangential direction does have an effect on the estimation of the maximum temperature within the components. This is the result of a better mapping of the temperature gradient within the component with an increasing amount of nodes. Within this verification case, the amount of nodes in the axial direction has a minor influence. However, it is expected that the effect will be more significant in cases where cooling methods are applied to the end windings because in those cases higher thermal gradients occur within the axial direction.

Taking this analysis into account, the verification of the LPM will be done with the following coarse discretization, which results in a total amount of 11909 nodes:

- Winding: 22 radial and 15 tangential,

- Stator pole: 21 radial and 8 tangential,

- Stator yoke: 11 radial and 14 tangential,

- Axial: 5 in the active region and 3 in the end windings.

II) 3D Finite Element Model:

To decide upon the amount of cells used within the 3D FE simulation, several simulations were carried out with an increasing amount of cells ranging from 24550 to 1580200 . The average and maximum temperature of the components for

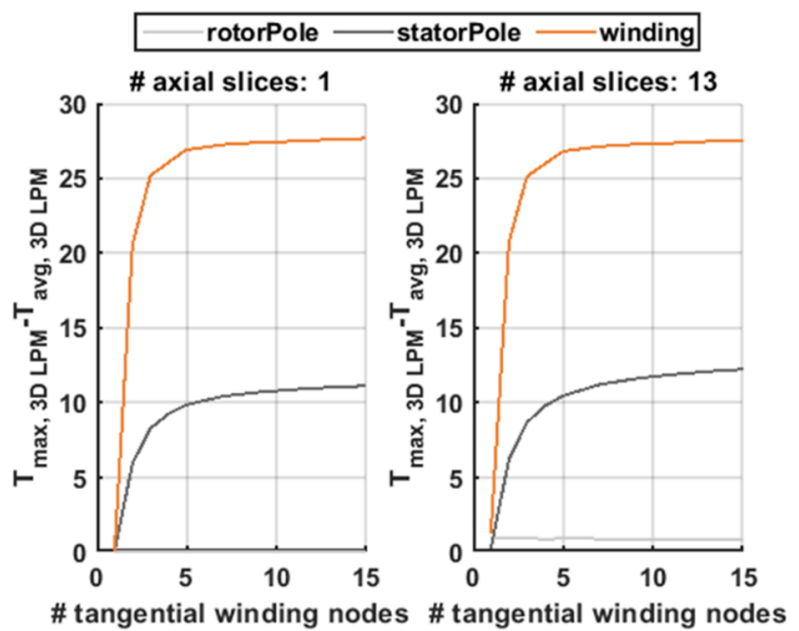

Fig. 5. Effect of the amount of radial, tangential and axial nodes on the maximum component temperature.

each of the simulations is shown in Fig. 6. The change in average and maximum temperature from the second-to-last simulation (666150 cells) to the last simulation (1.6 million cells) is smaller than the $0.1^{\circ} \mathrm{C}$ and therefore accepted as sufficiently accurate. Therefore, the results of the simulation with 666150 cells are used in the further analysis.

The build-in checkMesh utility of OpenFOAM is also used to verify the goodness of the mesh and no issues are detected within the mesh. The heat balance is checked after the calculation of the model (smaller than $0.001 \%$ ) and iterations are performed until the residuals on the enthalpy in each region are lower than $10^{-8}$.

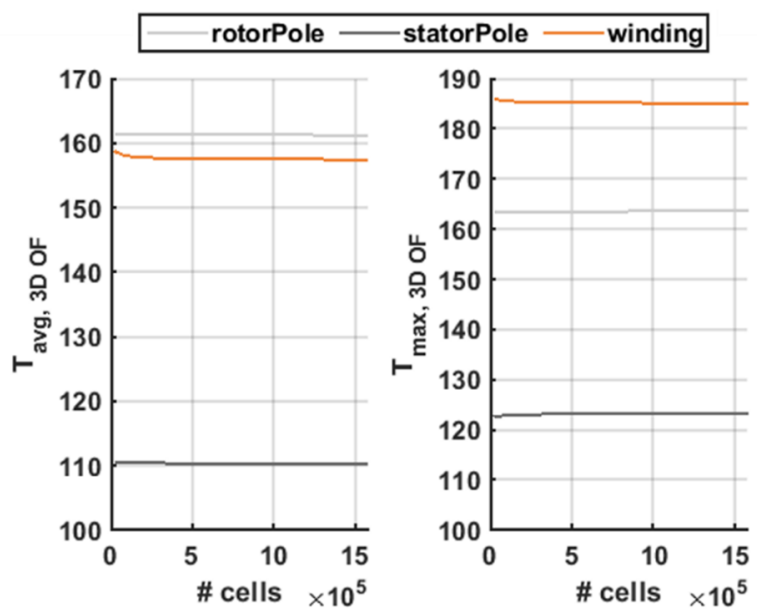

Fig. 6. Effect of amount of cells on the average (left) and maximum (right) component temperature in OpenFOAM

\section{B. Simulated temperature distribution plots}

With the discretization and mesh size as set in the previous section, firstly a temperature distribution plot of both models is shown to visually compare the thermal gradients within the motor. The two temperature distributions are shown in Fig. 7 with respectively the 3D LPM results on top and 3D FEM results at the bottom. The 3D LPM shows the temperature of the end plates, several end winding slices at both axial motor sides and several axial slices in the active part of the motor. Both figures use the same temperature scale and can thus be 

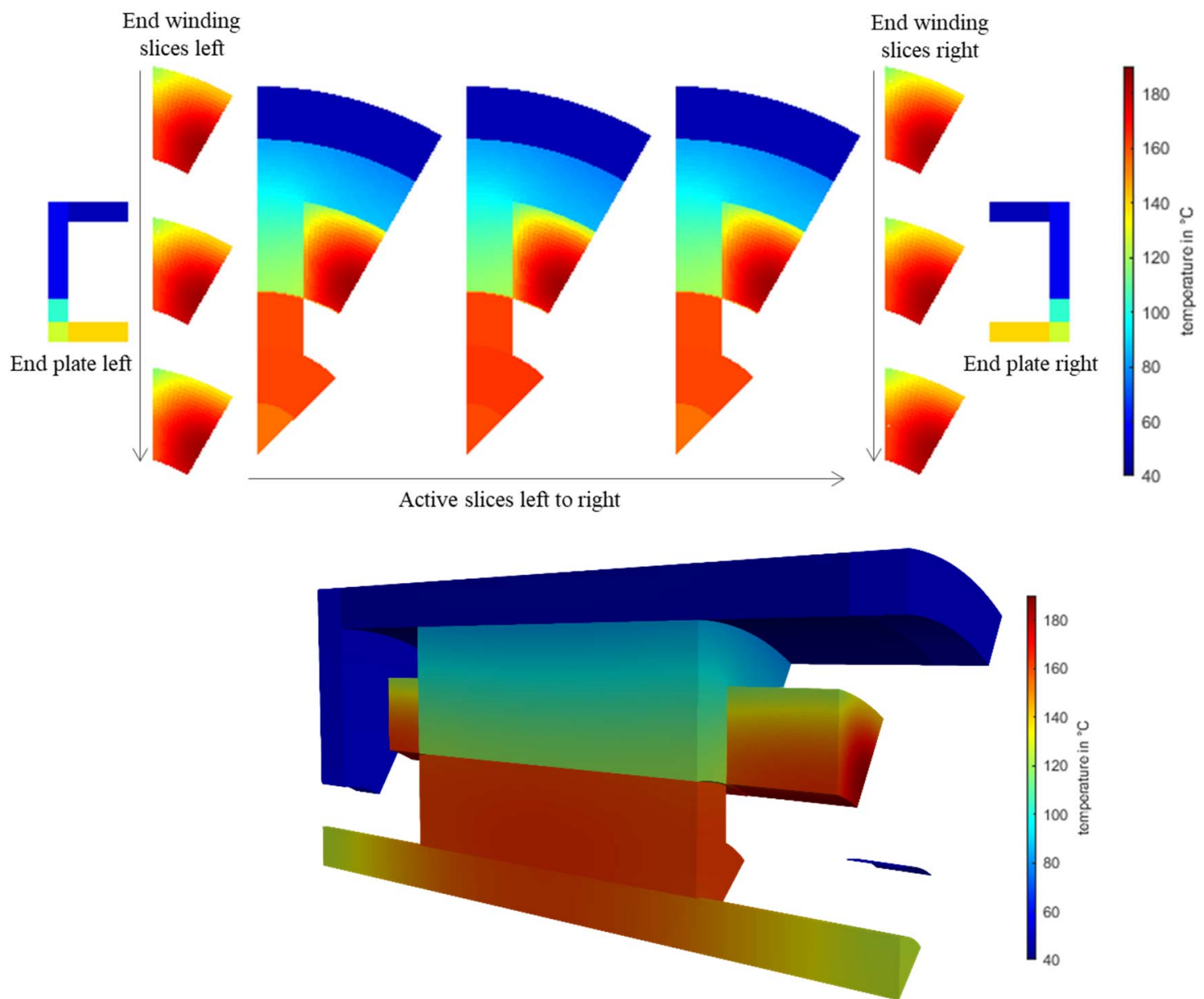

Fig. 7. Temperature distribution plots resulting from the 3D LPM (top) and 3D FE visualized in Paraview with the front flange hidden(bottom)

compared one to one. The comparison shows a very similar temperature distribution and no deviation can be observed visually, except for the more discrete temperature distribution in some of the components of the 3D LPM due to the coarse discretization.

\section{Model verification}

To verify the proposed 3D LPM in more detail, the average and maximum temperature of the different components resulting from the two models will be compared. Within TABLE III, the average component temperatures resulting from both models are shown, together with the absolute and relative deviations. The relative temperature deviation is defined as the temperature difference between the two models, divided by the temperature within the 3D FE model subtracted by the jacket coolant inlet temperature:

$\Delta T_{\text {rel }}=\left(T_{3 D L P M}-T_{3 D F E M}\right) /\left(T_{3 D F E M}-T_{\text {in,jacket }}\right)(12)$

The results of TABLE III are shown in Fig. 8 where the full green line shows the perfect match between the two models, while the dotted green lines indicate the range with a deviation of $\pm 2.7 \%$. The colors indicate the different components as indicated in the figure. The comparison shows that the 3D LP model simulates the average temperature of the motor components with a very high accuracy, more specifically within $0.6^{\circ} \mathrm{C}$ or $2.7 \%$ of the temperatures simulated by the 3D FE model. The highest relative deviation $(2.7 \%)$ occurs within the flanges, where the temperature is overestimated by $0.4^{\circ} \mathrm{C}$
TABLE III

COMPARISON OF 3D LPM AVERAGE TEMPERATURES WITH 3D FEM

\begin{tabular}{|l|c|c|c|c|}
\hline Component & $\begin{array}{c}\mathbf{T}_{\text {LPM,avg }} \\
\left({ }^{\circ} \mathbf{C}\right)\end{array}$ & $\begin{array}{c}\mathbf{T}_{\text {FEM,avg }} \\
\left({ }^{\circ} \mathbf{C}\right)\end{array}$ & $\begin{array}{c}\mathbf{T}_{\text {abs }} \\
\left({ }^{\circ} \mathbf{C}\right)\end{array}$ & $\begin{array}{c}\mathbf{T}_{\text {rel }} \\
(\boldsymbol{\%})\end{array}$ \\
\hline Shaft active & 157.4 & 156.8 & 0.6 & 0.5 \\
\hline Rotor yoke & 162.2 & 162.5 & -0.2 & -0.2 \\
\hline Rotor pole & 160.9 & 161.1 & -0.3 & -0.2 \\
\hline Stator pole & 110.4 & 110.3 & 0.1 & 0.2 \\
\hline Stator yoke & 85.3 & 85.2 & 0.1 & 0.1 \\
\hline Housing active & 47.4 & 47.4 & 0.0 & 0.4 \\
\hline Winding active & 157.6 & 157.4 & 0.2 & 0.2 \\
\hline End windings & 160.1 & 159.9 & 0.2 & 0.2 \\
\hline Housing end space & 48.1 & 48.0 & 0.1 & 0.6 \\
\hline Flange & 55.8 & 55.4 & 0.4 & 2.7 \\
\hline Shaft end space & 139.5 & 139.1 & 0.4 & 0.4 \\
\hline Shaft end plate & 126.5 & 126.7 & -0.2 & -0.3 \\
\hline
\end{tabular}

in the 3D LP model. This is however not an issue, since it is not a vulnerable component and the absolute temperature is low. For all other components (including the coil, stator and rotor), the relative deviation is smaller than $0.5 \%$.

Similar conclusions apply for the maximum temperature simulated by the 3D LPM and 3D FEM, which are shown in TABLE IV and Fig. 9. The simulated maximum temperatures by the 3D LPM are now within $8.8 \%$ of the simulated temperatures by the $3 \mathrm{D}$ FEM. The maximum deviation is slightly higher than for the average temperature and occurs at 


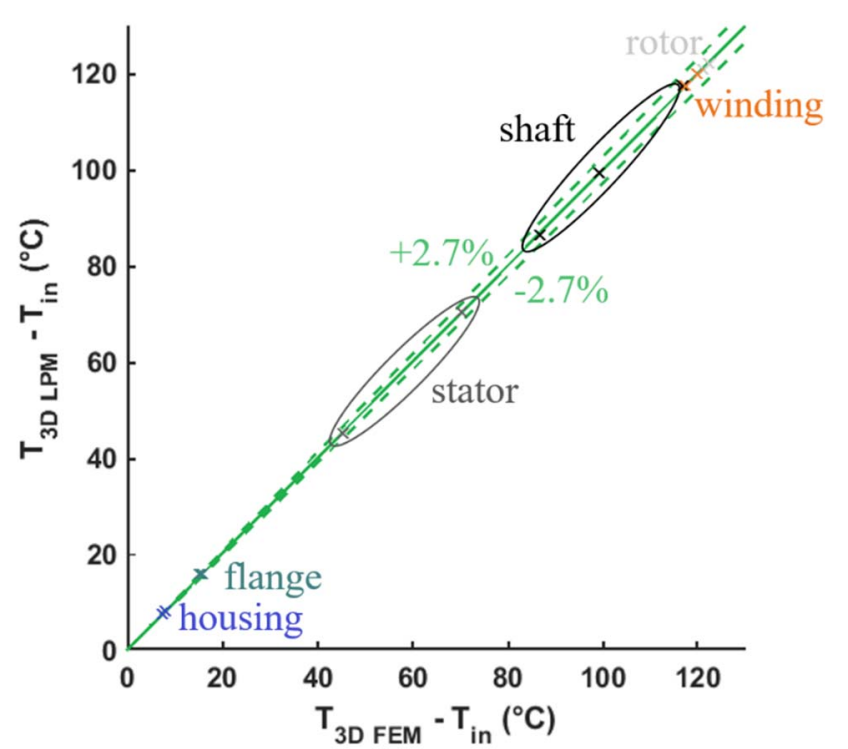

Fig. 8. Verification of 3D LPM average component temperature with 3D FE simulations.

TABLE IV

COMPARISON OF 3D LPM MAXIMUM TEMPERATURES WITH 3D FEM

\begin{tabular}{|l|c|c|c|c|}
\hline Component & $\begin{array}{c}\mathbf{T}_{\text {LPM, max }} \\
\left({ }^{\circ} \mathbf{C}\right)\end{array}$ & $\begin{array}{c}\mathbf{T}_{\text {FEM,max }} \\
\left({ }^{\circ} \mathbf{C}\right)\end{array}$ & $\begin{array}{c}\mathbf{T}_{\text {abs }} \\
\left({ }^{\circ} \mathbf{C}\right)\end{array}$ & $\begin{array}{c}\mathbf{T}_{\text {rel }} \\
(\mathbf{\%})\end{array}$ \\
\hline Shaft active & 160.2 & 160.2 & 0.0 & 0.0 \\
\hline Rotor yoke & 163.3 & 164.0 & -0.7 & -0.5 \\
\hline Rotor pole & 161.6 & 163.4 & -1.8 & -1.5 \\
\hline Stator pole & 122.2 & 123.1 & -0.9 & -1.1 \\
\hline Stator yoke & 96.8 & 97.6 & -0.8 & -1.4 \\
\hline Housing active & 47.6 & 48.2 & -0.6 & -7.5 \\
\hline Winding active & 185.1 & 185.0 & 0.1 & 0.1 \\
\hline End windings & 185.2 & 185.0 & 0.2 & 0.1 \\
\hline Housing end space & 48.1 & 48.4 & -0.3 & -3.5 \\
\hline Flange & 55.8 & 56.6 & -0.8 & -4.7 \\
\hline Shaft end space & 139.5 & 149.0 & -9.5 & -8.8 \\
\hline Shaft end plate & 126.5 & 129.2 & -2.7 & -3.0 \\
\hline
\end{tabular}

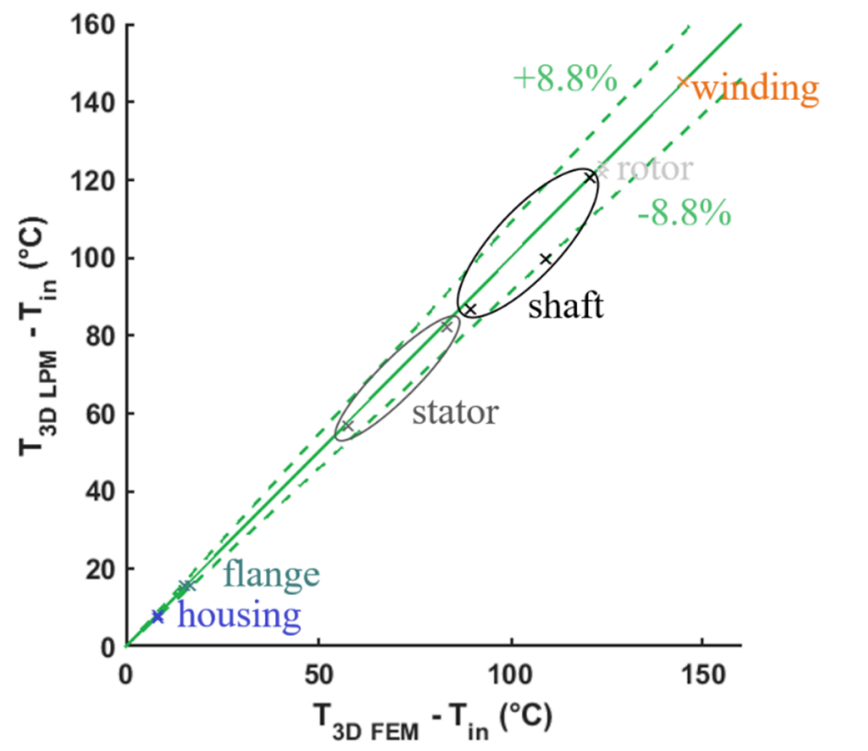

Fig. 9. Verification of 3D LPM maximum component temperature with 3D FE simulations

the housing, flange and shaft. However, for the housing and flange the absolute temperature deviation is smaller than $0.8^{\circ} \mathrm{C}$, but due to the small temperature difference between housing and coolant, the relative deviation is high. Furthermore, the higher deviation of the maximum temperature compared to the average temperature is a result of the temperature gradient within these components and the fact that within the 3D LPM, only one node is used for these whole regions. As a result, the 3D LPM cannot predict the maximum temperature accurately within these components. If a more accurate prediction of the maximum temperature in these component would be desired, additional nodes should be added as was done for the winding and stator iron.

In the components where the discretization was increased (winding and stator iron) the deviation is much smaller: $0.1 \%$ in the winding and $1.4 \%$ in the stator iron. This shows a proper working of the discretization strategy which has the purpose of accurately modelling the maximum temperatures.

\section{Causes of the deviations}

The comparison in the previous section shows that the $3 \mathrm{D}$ LP model is capable of predicting the average and maximum motor temperatures with a high accuracy, certainly for the important components (winding, stator iron and rotor iron). The existing deviations between the 3D LPM and 3D FEM are a result of the simplifications and assumptions that were used within the development of the 3D LPM:

- Within the 2D FE simulation with FEMM, no contact resistances can be applied between components. Therefore these are added later on within the LPM. As a result, a slightly deviating temperature gradient exists within the 2D FE simulation.

- The method developed by Wrobel et al. [14] to model nodes with internal heat generation is still an approximation of the actual heat transfer. Therefore deviations can be expected compared with a $3 \mathrm{D}$ FE model.

- As already mentioned in the previous section, for some components only one node is used. As a result, only one temperature is simulated for this region of the component and no differentiation is made between minimum, maximum and average temperatures.

- The extraction of the 2D LPM from the 2D FEM relies on an accurate integration of the average node temperatures and heat fluxes between the nodes. Numerical errors within FEMM can cause inaccuracies within the LPM. For example when the heat fluxes or temperatures differences are very small, the numerical error can be higher than these values.

- The heat transfer in the end spaces and end plates is approximated as 1D conduction, which is a simplification of the reality since $3 \mathrm{D}$ heat conduction will occur here.

Taking into account the above, this paper concludes that the proposed advanced 3D LPM is a very efficient and accurate method when compared to 3D FEM.

\section{CONCLUSION AND FUTURE WORK}

In this paper, a 3D LPM was developed to be able to study 
the impact of the thermal motor design modification on the motor temperature. The model extracts a 2D LPM from a 2D FE simulation in FEMM and extends this 2D LPM into 3D based on the regular LP techniques. Several simplifications and assumptions were introduced to be able to develop the 3D LP model, whose effect on the accuracy of the motor is verified. This verification is done based on a comparison of the simulated average and maximum component temperatures with the results of a 3D FE simulation in OpenFOAM. The comparison shows a very close match of the temperature distribution in the 3D LPM and the 3D FE model, with a deviation of $0.2 \%$ on the maximum of the average component temperatures (rotor) and $0.1 \%$ on the maximum of the maximum component temperatures (winding), relative to the coolant inlet temperature. These deviations show a proper working of the 3D LPM. When taking into account the simplifications and assumptions, it can be concluded that the 3D LPM is an efficient and accurate method when compared to $3 \mathrm{D}$ FEM.

In a continuation of this work, the $3 \mathrm{D}$ LPM will be verified more in detail by implementing improvements in the thermal design of the motor (direct cooling method on the windings, motor geometry,...) with the 3D FEM. After these additional verifications, an experimental setup will be built based on the results of the 3D LPM, with specific attention to the uncertainty on the thermal properties of interfaces and materials. Afterwards, the model can be used to choose and design the different thermal improvements while taking other parameters into account such as cost, practical feasibility and additional losses in the electric motor.

\section{REFERENCES}

[1] V. Madonna, P. Giangrande, A. Walker, and M. Galea, "On the effects of advanced end-winding cooling on the design and performance of electrical machines," in 2018 XIII International Conference on Electrical Machines (ICEM), 2018, pp. 311-317.

[2] Y. Gai, M. Kimiabeigi, Y. C. Chong, J. D. Widmer, X. Deng, M. Popescu, et al., "Cooling of automotive traction motors: schemes, examples, and computation methods," IEEE Transactions on Industrial Electronics, vol. 66, pp. 1681-1692, 2018.

[3]M. Schiefer and M. Doppelbauer, "Indirect slot cooling for high-powerdensity machines with concentrated winding," in 2015 IEEE International Electric Machines \& Drives Conference (IEMDC), 2015, pp. 1820-1825.

[4]M. Popescu, D. A. Staton, A. Boglietti, A. Cavagnino, D. Hawkins, and J. Goss, "Modern heat extraction systems for power traction machines-A review," IEEE Transactions on Industry Applications, vol. 52, pp. 2167$2175,2016$.

[5]L. Siesing, A. Reinap, and M. Andersson, "Thermal properties on high fill factor electrical windings: Infiltrated vs non infiltrated," in 2014 International Conference on Electrical Machines (ICEM), 2014, pp. 22182223 .

[6]C. Tighe, C. Gerada, and S. Pickering, "Assessment of cooling methods for increased power density in electrical machines," in 2016 XXII International Conference on Electrical Machines (ICEM), 2016, pp. 26262632.

[7] S. Nategh, A. Boglietti, D. Barber, Y. Liu, and R. Brammer, "Thermal and Manufacturing Aspects of Traction Motors Potting: A Deep Experimental Evaluation," IEEE Transactions on Energy Conversion, 2020.

[8]S. A. Semidey and J. R. Mayor, "Experimentation of an electric machine technology demonstrator incorporating direct winding heat exchangers," IEEE Transactions on Industrial Electronics, vol. 61, pp. 5771-5778, 2014.

[9]D. Tanguy, S. HARMAND, J. PELLE, and R. YU, "Experimental study of oil cooling systems for electric motors," Applied thermal engineering, vol. 71, 2014.
[10] M. Polikarpova, "Liquid cooling solutions for rotating permanent magnet synchronous machines," 2014.

[11] J. Pierre-Olivier and L. B. Jean, "HEAT TRANSFER IN ELECTRIC MACHINES," 2017.

[12] J. Nonneman, S. Schlimpert, I. T'Jollyn, and M. De Paepe, "Modelling and Validation of a Switched Reluctance Motor Stator Tooth with Direct Coil Cooling," in 2020 19th IEEE Intersociety Conference on Thermal and Thermomechanical Phenomena in Electronic Systems (ITherm), 2020.

[13] M. N. F. Ibrahim and P. Sergeant, "Prediction of Eddy Current Losses in Cooling Tubes of Direct Cooled Windings in Electric Machines," Mathematics, vol. 7, p. 1096, 2019.

[14] R. Wrobel and P. Mellor, "A general cuboidal element for threedimensional thermal modelling," IEEE Transactions on Magnetics, vol. 46, pp. 3197-3200, 2010.

[15] D. Staton, A. Boglietti, and A. Cavagnino, "Solving the more difficult aspects of electric motor thermal analysis in small and medium size industrial induction motors," IEEE Transactions on Energy conversion, vol. 20, pp. 620-628, 2005.

[16] K. Bennion, "Electric Motor Thermal Management R\&D," 2016.

[17] K. Kiyota, T. Kakishima, and A. Chiba, "Estimation and comparison of the windage loss of a $60 \mathrm{~kW}$ Switched Reluctance Motor for hybrid electric vehicles," in 2014 International Power Electronics Conference (IPECHiroshima 2014-ECCE ASIA), 2014, pp. 3513-3518.

[18] M. Bouafia, Y. Bertin, J. Saulnier, and P. Ropert, "Analyse expérimentale des transferts de chaleur en espace annulaire étroit et rainuré avec cylindre intérieur tournant," International journal of heat and mass transfer, vol. 41, pp. 1279-1291, 1998.

\section{BIOGRAPHIES}

Jasper Nonneman $\left({ }^{\circ} 1993\right)$ received his Master of Science degree in Mechanical Energy Engineering in 2016, from the Faculty of Engineering and Architecture, Ghent University, Belgium. He is currently working as a $\mathrm{PhD}$ researcher at the research group Sustainable Thermo-Fluid Energy Systems of the Department of Electromechanical, Systems and Metal Engineering at Ghent University, Belgium. His research interests are the cooling and thermal modelling of electric machines and power electronics.

Ilya T'Jollyn ( $\left.{ }^{\circ} 1992\right)$ received his Master of Science degree in Electromechanical Engineering from the Faculty of Engineering and Architecture, Ghent University, Belgium in 2014. He is currently a teaching assistant and $\mathrm{PhD}$ candidate in the research group Sustainable Thermo-Fluid Energy Systems of the Department of Electromechanical, Systems and Metal Engineering at Ghent University. His research interests include heat transfer in electrical machines and systems and he is currently working on two-phase power electronics cooling and innovative motor cooling techniques..

Peter Sergeant received the M.Sc. degree in electromechanical engineering and the Ph.D. degree in engineering sciences from Ghent University, Ghent, Belgium, in 2001 and 2006, respectively. He is currently a Professor in electrical drives with Ghent University and the Core Lab Manager with the Cluster Motion Products of Flanders Make, Lommel, Belgium. In 2001, he became a Researcher with the Electrical Energy Laboratory, Ghent University. He became a Postdoctoral Researcher with Ghent University in 2006 (Postdoctoral Fellow of the Research FoundationFlanders). Since 2012, he has been an Associate Professor with Ghent University. His current research interests include electrical machines and drives for industrial and sustainable energy applications, with emphasis on accurate computation of losses in machines and drives, improving energy efficiency, and increasing power density.

Michel De Paepe ( ${ }^{\circ} 1972$ ) is professor of Thermodynamics and Heat Transfer at the Faculty of Engineering and Architecture of the Ghent University. He graduated as Master of Science in Electromechanical Engineering at the Ghent University in 1995. In 1999 he obtained a PhD in Electromechanical Engineering at the Ghent University, graduating on 'Steam Injected Gas Turbines with water Recovery'. He is currently the head of the Research Group Applied Thermodynamics and Heat Transfer at the Faculty of Engineering and Architecture of the Ghent University. Research in this group focuses on: thermodynamics of new energy systems, performance of HVAC systems and energy in buildings and complex heat transfer phenomena in industrial applications, as in compact heat exchangers, combustion engines, electrical drives, refrigerant two-phase flow and electronics cooling. Prof. De Paepe was supervisor/promotor of $20 \mathrm{PhDs}$ defended at Ghent University. Prof. De Paepe is (co)author of 120 papers published in international peer reviewed journals and more than 350 conference papers. 